\title{
AFLES's Inspirations and Its ASEAN Youth Community Development (ASEAN Future Leaders Summit)
}

\author{
Anees Janee Ali ${ }^{1 *}$, Shabana Gul Sarang ${ }^{1}$, Mohamad Ali Sarvghadi ${ }^{1}$, Jamshed Khalid ${ }^{1}$, Brandon May ${ }^{1}$ \\ ${ }^{1}$ Universiti Sains Malaysia (USM) \\ *aneesali15@yahoo.com
}

\begin{abstract}
This article is discussing about experiences of conducting AFLES (ASEAN Future Leaders Summit), which started in 2013 with the collaboration between Universiti Sains Malaysia (USM) and Prince of Songkla University, Thailand (PSU). AFLES is an action-packed summit meant for ASEAN youth with exciting forums, discussions, lectures, team-work, outdoor activities, community work, services, sight-seeing and cultural events. With the main objectives of developing ASEAN youth community in terms of their leadership skills and to serve as a platform for ASEAN youth to get together and connected to each other, AFLES for the last sixth term (2013-2018), has evolved to be a looking after summit to participate by ASEAN university student leaders. Over the years AFLES has developed and progressed with a few more collaborators, namely AKEPT (Malaysia Higher Education Leadership Academy), UiTM (Universiti Teknologi MARA), UUM (Universiti Utara Malaysia) and UKM (Universiti Kebangsaan Malaysia). Community development, ASEAN unity and harmonization, and Internationalization of Higher Education Institutions in ASEAN are discussed regarding to the sustainability of AFLES in conducting an international program for youth across ASEAN region.
\end{abstract}

Keywords: AFLES (ASEAN Future Leaders Summit), ASEAN Unity and Harmonization, Community development, Internationalization of Higher Education Institutions

\section{INTRODUCTION}

AFLES (ASEAN Future Leaders Summit) is a fruit of three combination agendas: Community development that involve ASEAN youth; ASEAN's unity and harmonization agenda that focus on ASEAN youth; and Internationalization of ASEAN Higher Education Institutions and Students, which are going to be discussed below.

\section{Community Development}

The United Nations defines community development as "a process where community members come together to take collective action and generate solutions to common problems". It is a broad term given to the practices of civic leaders, activists, involved citizens and professionals to improve various aspects of communities, typically aiming to build stronger and more resilient local communities (https://en.wikipedia.org/wiki/Community_development). The International Association for Community Development, the global network of community development practitioners and scholars defined community development, as "a practice-based profession and an academic discipline that promotes participative democracy, sustainable development, rights, economic opportunity, equality and social justice, through the organisation, education and empowerment of people within their communities, whether these be of locality, identity or interest, in urban and rural settings" (www.iacdglobal.org).

As explained by Scottish Community Development Community (SCDC), Good community development is action that helps people to recognise and develop their ability and potential and organise themselves to respond to problems and needs which they share. It supports the establishment of strong communities that control and use assets to promote social justice and help improve the quality of community life. (http://www.scdc.org.uk/who/what-is-community-development/). Community development seeks to empower individuals and groups of people with the skills they need to effect change within their communities (https://en.wikipedia.org/wiki/Community_development). These 
skills are often created through the formation of social groups working for a common agenda. Community development ranges from small initiatives within a small group to large initiatives that involve the broader community. That is what AFLES is all about, starting from a small initiative in a small group that serves a large group of community, that is, ASEAN youth.

\section{ASEAN Community: Unity and Harmonization}

The ASEAN Community 2015 is a community of opportunities under three community pillar: political-security, economic and socio-cultural. (ASEAN.org/storage/2012/05/7.-Fact-Sheet-onASEAN-Community.pdf). Considering that ASEAN motto is "One Vision, One Identity, One Community", it is the right time for ASEAN countries to make way of closer relationships among the ten country members and the founder of AFLES (Anees Janee Ali) believes that the good relationship among ASEAN countries should start from the early age. The founder of AFLES believes that ASEAN youth, who are going to the leaders in the future should be exposed and introduced to each other in one platform. This is parallel with the ASEAN's mission in harmonizing the society of ASEAN. AFLES's founder had a few opportunities to have meetings with several ASEAN's universities top management and also the directors of International Office of the universities and noticed the "harmonization" issues during the decision making of the meetings. This had triggered ideas to him to start a platform to gather ASEAN youth together and to start knowing and learning from each other.

\section{Internationalization of Higher Education Institutions (HEIs) in ASEAN}

Internationalization is the process of integrating an international or intercultural dimension into the teaching, research, and service functions of an institution of higher learning (Knight, 1993, p. 21). Knight and De Wit (1999) mentioned that internationalization of Higher Education Institutions will involve:

- Academic (new knowledge, applications for knowledge, international intellectual interaction)

- Socio-cultural development (equality, justice, inter-cultural understanding)

- Political (peace and security, global positioning, workforce development) - Economic (global competition, preparing students for employment the global context). As discussed by Tahira Jibeen and Masha Asad Khan (2015), the internationalization of education facilitates in engendering the "international characteristics" fostered in students that are desirable in a global economy such as international-mindedness and open mindedness, second language competence, flexibility of thinking, tolerance and respect for others (Hayden, Thompson, \& William, 2003; Chan \& Dimmock, 2008). They further discussed that this phenomenon also develops ethical commitment to allow students to examine their implicit and explicit beliefs and develop a sense of responsibility and civic engagement (Kreber, 2009).

One of the activities that ASEAN students can be "internationalized" is through participating in the student exchange program or short program organized in other host countries or international programs organized at their own home country (which is known as Internationalization at Home). AFLES is a summit meant for ASEAN student leaders/youth from ASEAN HEIs across the region that ASEAN students can participate and develop themselves to be "internationalized" and a knowledgeable global citizen.

\section{Introduction to AFLES (ASEAN Future Leaders Summit)}

ASEAN Future Leaders Summit (AFLES) is an exciting leadership summit that invites student leaders, both undergraduates and postgraduates from universities across ASEAN as well as other nations. AFLES has the main aim to enrich ASEAN students with leadership qualities and capabilities. This summit intends to create a networking platform for ASEAN delegates to share ideas and knowledge on critical issues of ASEAN higher education, leadership and students' participation activities in creating a sustainable tomorrow for the ASEAN young generation.

AFLES started with a simple discussion between Universiti Sains Malaysia (USM), represented by Associate Professor Dr. Anees Janee Ali and Prince of Songkla University (PSU), Thailand represented by Associate Professor Dr. Ram Yamsaengsung back in 2013, both back then were the directors of International Office of respective universities. The fruit from this meeting was a leadership program for students between USM and PSU. After the program ended, Anees Janee Ali who had the 
idea of bringing ASEAN youth together and realizing that this program could be organized at higher level, that is, for ASEAN students, Anees Janee Ali proposed to Ram Yamsaengsung to collaborate and conduct a leadership summit catered for ASEAN youth. Both of them realized the needs and importance for ASEAN students to get together on one platform that could be a way to foster for the betterment of ASEAN. Then, AFLES (ASEAN Future Leaders Summit) was born with USM as the main committee, led by USM Postgraduate Students Association (USM-PSA) and PETAS (USM Non-hostelite Students Association).

In terms of collaboration, AFLES has developed from only two main collaborators in AFLES 2013 into six main collaborators in AFLES 2018. It started with only two collaborators, namely USM and PSU and in 2014, AKEPT (Malaysia Higher Education Leadership Academy) has joined in as a collaborator and has been the main sponsor of AFLES since 2014 until 2018. Universiti Sains Islam Malaysia (USIM) also joined in as the collaborator in the same year but only in 2014. In 2015, Universiti Teknologi MARA (UiTM) and Universiti Utara Malaysia (UUM), upon invitation agreed to participate as AFLES collaborators. Both universities have been the co-organisers until 2018. AFLES 2018 welcomed a new collaborator, that is, Universiti Kebangsaan Malaysia (UKM). USM as the main organizer is led by the USM-Postgraduate Student Association (USM-PSA) and also PETAS (Nonhostelite USM Students Association), which are booth are led by USM students.

\section{AFLES and its Community Development}

AFLES's vision is to foster mutual relationships and create a sustainable network among ASEAN youth through activities of leadership enrichment skills to prepare them to lead in ASEAN education and society in the future. Among the main objectives of AFLES are:

- To bring ASEAN youth community under one platform aiming to enrich their leadership capabilities and to promote effective ASEAN youth networking

- To develop ASEAN youth community in terms of their leadership skills and to create meaningful activities for ASEAN student leaders

- To engage and nourish communication among ASEAN youth community, especially to ASEAN university student leaders

- To serve as a platform for ASEAN future leaders to get together and create close relationship among each other hoping to be beneficial in bringing ASEAN forward

- To impart ASEAN leadership transformations among ASEAN youths and to prepare them for social leadership in the future

- To foster cross cultural learning and understanding for betterment of ASEAN development

- To provide a platform for ASEAN student leaders community to share useful ideas to move ASEAN forward

- To showcase ASEAN youths' leadership talents through community service, presentations, discussions, ASEAN Gala Night and Cultural Exhibition and creating new networking opportunities of ASEAN youth community.

- To develop and nurture friendship and strong ties among leading universities in the ASEAN region through the participations of the delegates from different universities and higher education institutions across ASEAN

- To engage ASEAN youth community in long term relationship for ASEAN networking and to publish articles about AFLES in their own respective countries.

With a theme, Building Leadership for Sustainable Tomorrow, AFLES hopes that this summit will create strong establishment for ASEAN young leaders' community as committees to carry out future projects in their own respective countries.

\section{The Uniqueness of AFLES}

AFLES has become a popular and looking forward leadership event for university students and youths across ASEAN. The words of mouth of previous delegates of AFLES have been spread across ASEAN and some applicants have started to make preparation a year before the summit starts like 
joining in community activities in their own countries so that they can write about these activities in the AFLES application form. This is because the applicants know that the selection process is tight and many applicants would like to join this summit.

AFLES is fast in gaining popularity as a leadership summit among youths of ASEAN because of its uniqueness. AFLES is unique in so many ways:

- AFLES gathers delegates of student leaders from around the ten ASEAN countries plus other nations in the Asia Pacific

- Besides being a leadership summit, AFLES promotes better understanding of ASEAN and its unity and harmonization

- AFLES is a collaboration of six institutions in two ASEAN countries, which are USM, AKEPT, UiTM, UUM and UKM in Malaysia, and PSU in Thailand. When AFLES started in 2013, it has only two collaborators and in 2018, AFLES has six collaborators across two countries.

- AFLES exposes its delegates to two different countries with two significant different cultures and languages

- AFLES takes a duration of almost 2 weeks in which delegates spend 5 days at AKEPT in Nilai, 2 days at UiTM Shah Alam, 3 days at USM in Penang, half day at UUM in Sintok and the last 3 days at PSU in Hatyai, Thailand

- AFLES introduces its delegates to workshop, talks, discussions, forums, educational visits, competitions, cultural exhibition and cultural performance. ASEAN Gala Night is the cultural performance night of the delegates. The delegates of each country perform cultural show and they have been in contact with each other about two months before AFLES starts. The delegates are from different cities and universities and these two months are taken by them to prepare for AFLES to do presentations and of course to practice for the ASEAN Gala Night. The outcomes of these preparation and practice are creative, awesome, interesting, informative and professional-like performance.

- The main committee members of AFLES are international and local students of USM and most of them are from the non-ASEAN countries such as Iran, Pakistan, Iraq, India, Syria, Palestine, India, Yemen, Egypt, and of course Malaysia. This diverse group of committee members brings about high level of creativity and exciting working environment.

\section{Historical Background of AFLES and AFLES 2013-2018}

\section{AFLES 2013 (1st AFLES)}

Anees Janee Ali together with Mohammad Thaif (from India) as the first director of AFLES, started conducting the ground work of AFLES. In order to get fast response, the committee members used Facebook to advertise AFLES 2013. Surprisingly, within two weeks of promoting AFLES, more than 800 students applied. This high number of applicants showed of how eager the university students of ASEAN to participate in a program that involves other ASEAN nations. During this period, we could hardly see programs involving ASEAN students and this probably had created so much interest among them. The applicants of AFLES had to go through a tight selection process in which their application forms were examined thoroughly. Applicants must provide information such as background, year of studies, activities that they had conducted at universities and communities. In addition, applicants must write an essay stating their motivation, hopes and outcomes of joining AFLES. Out of these 800 applicants, the committee chose only 100 participants. The first AFLES (AFLES 2013) was a seven day program in which delegates spent four days at USM in Penang and the next three days at PSU in Hat Yai. During the 1st AFLES, delegates were exposed to leadership talks, discussions and forums from various professors and corporate figures. Associate Professor Dr Nantana Gajaseni, the Director of ASEAN University Network graced AFLES 2013 by launching the program and gave a talk about the development and future of ASEAN youth. AFLES 2013 received many great reviews from the delegates and they spread the news of AFLES. The great outcomes of AFLES 2013 motivated the committee members to continue conducting AFLES in the coming years. 


\section{AFLES 2014 (2nd AFLES)}

The 2nd ASEAN Future Leaders Summit (AFLES 2014) took a big leap. Associate Professor Dr Zainal Sanusi, was then the deputy director of AKEPT heard about AFLES and invited the committee members to collaborate with AKEPT. Collaboration with AKEPT has brought AFLES to a higher level and made it becoming more prestigious. Ehsan Khoyadari (from Iran), was then an undergraduate student of School of Management, Universiti Sains Malaysia took the batons to become the director of AFLES 2014. The committee members then invited Universiti Sains Islam Malaysia (USIM) to become the next AFLES 2014 collaborator. AFLES 2014 had four collaborators, with USM as the leader, followed by PSU, AKEPT and USIM. More activities were created and the summit was extended to ten days. This collaborations had lifted AFLES to become a more prestigious leadership program for ASEAN youths. Within one month of promotion, around 500 ASEAN students applied to join this exciting program and 100 participants were selected.

\section{AFLES 2015 (3rd AFLES)}

The 3rd AFLES (AFLES 2015) took another big leap. Since there were about 500 applicants, the committee members had decided to increase the number of delegates. AFLES 2015 received 160 delegates and Imran Serwar (a USM PhD Pakistani student) was the director of AFLES this time. UiTM was invited to be the new collaborator for AFLES 2015. Spending 11 days with us, the delegates were exposed to more exciting new activities such as team-building activities at ESCAPE in Penang.

\section{AFLES 2016 (4th AFLES)}

The 4th AFLES (AFLES 2016) was led by Mohammad Ali Sarvghadi (an Iranian USM PhD student). 160 delegates across ASEAN were invited to join this 11-day summit plus 2 delegates from Pakistan. AKEPT has become the major sponsor of this summit and decided to make AFLES as an annual flagship activity of AKEPT. A one-day workshop on ASEAN leadership was included this time together with another team-building activity at Lost World of Tambun and ESCAPE, and teamrafting activity in Songkhla province in Thailand. Delegates learnt new leadership concepts from invited speakers and at the same time through the team-building activities, closer relationships among ASEAN delegates were created.

\section{AFLES 2017 (5th AFLES)}

The 5th AFLES (AFLES 2017) once again directed by Mohammad Ali Sarvghadi. AFLES 2017 saw an increase in the number of delegates to 170 participants. Interesting talks, discussions and presentations by professors and corporate figure benefited delegates and opened their minds of how to increase their leadership capabilities and qualities in moving ASEAN forward. Community service project presentations of each country had given ideas to other delegates of how they can create other interesting community service projects in their own countries. Educational visits to BEM (Education Malaysia Department) at Malaysia Higher Education in Putrajaya, Putrajaya itself, UNESCO World Heritage City of Melaka and Penang introduced the delegates to many interesting facts and visual stimulations. In addition, AFLES delegates were exposed to cultures of Malaysia and Thailand by presentations of the delegates from Malaysia and Thailand. One of the major highlight of AFLES are the cultural exhibition and ASEAN Cultural Gala Night. The delegates of AFLES 2017 from the ten countries represented their history, culture, traditions and traditional foods and games on their respective booths for cultural exhibition. The exciting ASEAN Cultural Gala Night performances of the ASEAN region touched the hearts of the audience. From the Gala Night and cultural booths, delegates of AFLES 2017 have learnt many different stories and cultures of ASEAN. In the community service conducted in the province of Songhkla, Thailand of releasing millions of baby crabs into the Gulf of Thailand and planting mangrove trees had created new experiences to the delegates. Overall, the 5th AFLES was another successful event organized by USM (USM-PSA), AKEPT, PSU, UiTM and UUM. The continuous guidance and advise and continuous hard work of Director of AFLES 2017, Mr. Mohammad Ali Sarvghadi had made AFLES 2017 a successful and fruitful international event for ASEAN youths. 


\section{AFLES 2018 (6th AFLES)}

AFLES 2018 (22 July- 3 August 2018) has seen an increase in the number of delegates. AKEPT's top management ideas in increasing the number of AFLES delegates has managed to gather 180 delegates across ASEAN, with 20 main committee members from USM. The new Malaysia Minister of Education, Dr Mazlee Malik has launched the summit with a very moving and inspirational talk to the delegates. Delegates were motivated with inspirational speakers from all walks of life, from Vice Chancellors to Professors, from young Entrepreneurs to Malaysia students' icons. Delegates made presentations of community service that they had conducted in their respective countries. Delegates were enchanted with a new way of team building at Tambun and also at ESCAPE in Penang, a team building center that challenge them physically and mentally. Delegates were made busy and excited with cultural exhibition of each country and to showcase cultural performance that wowed everyone in the hall. Go-cart session at UUM has increased confidence level among delegates. PSU has introduced the tourism industry to delegates by having discussion and presentation on that topic. Community service by cleaning Sharmila Beach has made delegates excited and having extra time to work as a team regardless of nationalities. Farewell dinner closed AFLES 2018 that left delegates with memories that they are able to contribute for the betterment of ASEAN community.

\section{Lessons Learnt to Make AFLES Sustainable}

AFLES is an active summit catered to the needs of ASEAN youth and the committee wish it can sustain for the years to come. AFLES is a platform where young leaders of ASEAN countries get together to represent and speak up for their countries and show the world that they are leading a bright future. Education often leads to theories but through AFLES, it is informal way of learning and AFLES shows and lead the delegates into the reality of life. Every single delegate during this summit must lead $\mathrm{him} /$ herself , their team nation and the whole group of delegates.

There are a few elements that can make AFLES sustainable. Among the elements are:

\section{Collaborations}

As mentioned by Wood (2017), one way of beginning to form working relationships with prospective community participants is to engage with the so-called 'third sector' (Erasmus and Albertyn, 2014), or Non-Governmental Organizations (NGOs). In this case, AFLES committee has made connection with AKEPT (Malaysia Higher Education Academy) during the process of conducting the second AFLES in 2014. It was a great change to have met the top management of AKEPT and discussed with them about AFLES. Later, they agreed to be the main sponsor of AFLES and let us conduct AFLES at their premise and use their facilities such as accommodation, halls and café which is located at Nilai, Negeri Sembilan. This collaboration has raised AFLES to the next level and committee members were excited about this development. Not forget to mentioned that AFLES started in 2013 with the collaboration between USM and PSU and this great collaboration continues until nowadays. Along the way, USIM, UiTM, UUM and UKM were invited to join as collaborators so that AFLES delegates will have more creative activities to participate during the summit.

\section{Taking advantage of social media}

The power of social media of getting attentions of society/community is huge (Matthews, 2016) and AFLES committee organizer has taken advantage of this. During the first AFLES in 2013, the committee tried to get delegates by sending invitation letters to top management of universities across ASEAN but the responses were very slow. Thus, AFLES committee decided to create an account with Facebook and promoted AFLES through Facebook and it worked! Within two weeks, about 800 students applied to join AFLES which was a big surprise. Probably at that time in 2013 this kind of summit or program for ASEAN students were non-existence. It also indicated that ASEAN students' community are eager to join this kind of summit/program that is catered for their own needs.

\section{Creative and interactive activities}

AFLES has increased its values by having more interactive activities such as presentations, group discussion, team building, cultural performances, educational visits and sharing experiences. These 
activities may enhance AFLES delegates' analytical thinking, critical thinking, teamwork, level of empathy and most importantly, good friendship and relationship among the ASEAN delegates, which is the main objectives of AFLES.

Youth nowadays like interactive activities more than just listen to talks or sit in a classroom. Realizing this, AFLES committee utilizes this fact and set the activities of the summit around it. If we can make artificial intelligence for connection? Why don't we connect people with more real interaction? Our world is heading to 21 st century where man is more relying on device for interaction. This is how we are losing the real conversation over virtual conversation. At this point, AFLES provides the platform that everyone can voice out their thoughts, feelings and experience. In addition, AFLES delegates are asked to share their experiences in conducting community service in their own home country which may be examples and give ideas of what delegates from other nations could do in their community. Exciting presentations to showcase their community service have opened eyes of other delegates that they are capable of doing many things to contribute to the nations. An example, delegates from Myanmar shared their work helping the needy during the funeral ceremony, which inspires many delegates from other nations.

\section{Networking with other stakeholders}

Since AFLES is a community development program for ASEAN, thus it should include various stakeholders, that is, the community that ASEAN youth are living with. Thus, networking with various stakeholders is important in order to invite them to share their experiences and expertise with the AFLES delegates. Speakers of various background are invited to share their experiences with AFLES delegates. The speakers are from Ministry of Education, vice chancellors and professors at universities, successful entrepreneurs, students' leaders and icons, health and safety practitioners, villagers with their own village industries and many others. The shared experiences and expertise inspires delegates in so many ways and motivate them to contribute to their community and at the same time be a good citizen with global mindset.

\section{Continuous relationship with AFLESers}

We can continuously increase the level of awareness of AFLESers regarding the importance of the collaboration of the ASEAN countries, the new era's role of uniting ASEAN countries as a whole, and staying connected in peace and harmony. Following their updates of their individual success and group activities in their home country would bear satisfaction feelings to AFLES committee knowing that AFLESers are active and contribute to their own community. One suggestion is to organise AFLESers from different ASEAN countries in a group and ask them to conduct a program. They collaborate and share workload together and committee can observe the intergroup work together in peace and harmony.

\section{Great and dedicated committee members}

AFLES since 2013 until 2018 has been led by highly committed committee members. The good feedback and responses of the AFLES delegates from 2013 until 2018 showed their excitement and satisfaction of AFLES's programs and activities. This embedded high hopes and motivation among AFLES committee members for the future of AFLES in the years to come. The organizing committee of AFLES from 2013 to 2018 deserves great appreciation for their support and contribution towards this summit.

\section{CONCLUSION}

AFLES is an action-packed summit with exciting forums, discussions, lectures, team-work, outdoor activities, community work, services, sight-seeing and cultural events. The main purpose of the activities is to boost the motivation among the youths of ASEAN with the awareness that all of them have the potential to be leaders. This summit is timely as the ASEAN region is focusing on leadership training for its youth who will lead their respective countries in the future. We cannot deny that changes are bound to happen and in view of this, we need to prepare ASEAN youth to face the unpredictable challenges that will come their way. It is undeniable that AFLES is making its own history and has 
become a prominent event among student leaders in the ASEAN region.

\section{REFERENCES}

Chan, W. W., \& Dimmock, C. (2008). The internationalization of universities: Globalist, internationalist and translocalist models. Journal of Research in International Education, 7(2), 184-204.

Erasmus, M., \& Albertyn, R. (Eds.). (2014). Knowledge as enablement: Engagement between higher education and the third sector in South Africa. African SUN MeDia.

Hayden, M., Thompson, J., \& Williams, G. (2003). Student perceptions of international education Stitle a comparison by course of study undertaken. Journal of Research in International Education, 2(2), 205-232.

Knight, J. (1993). Internationalization: management issues and strategies. International education. CBIE.

Knight, J. (1999). Quality and Internationalisation in Higher Education. Paris, Organisation for Economic Cooperation and Development.

Kreber, C. (2009). Different perspectives on internationalization in higher education. New directions for teaching and learning, 2009(118), 1-14.

Matthews, P. (2016), "Social media, community development and social capital", Community Development Journal, 51(3)

Jibeen, T., \& Khan, M. A. (2015). Internationalization of higher education: Potential benefits and costs. International Journal of Evaluation and Research in Education (IJERE), 4(4), 196-199.

Yeravdekar, V. R., \& Tiwari, G. (2014). Internationalization of higher education and its impact on enhancing corporate competitiveness and comparative skill formation. Procedia-Social and Behavioral Sciences, 157, 203-209.

Wood, L. (2016). Community development in higher education: how do academics ensure their community-based research makes a difference?. Community Development Journal, 52(4), 685701.

https://www.nti.org/learn/treaties-and-regimes/association-southeast-asian-nations-ASEAN/

https://en.wikipedia.org/wiki/Community_development

www.iacdglobal.org

http://www.scdc.org.uk/who/what-is-community-development/

https://en.wikipedia.org/wiki/Community_development

ASEAN.org/storage/2012/05/7.-Fact-Sheet-on-ASEAN-Community.pdf 